\title{
Child abuse: perception and knowledge by Public Health Dentistry teams in Brazil
}

\author{
Mariana Dalledone ${ }^{1}$, Ana Paula Borges de Paola ${ }^{1}$, Gisele Maria Correr ${ }^{1}$, Eduardo Pizzatto ${ }^{1}$, \\ Juliana Feltrin de Souza', Estela Maris Losso ${ }^{1}$
}

${ }^{1}$ Universidade Positivo - UP, Dental School, Area of Pediatric Dentistry, Curitiba, PR, Brazil

\begin{abstract}
Aim: To evaluate the experience, knowledge and attitudes of dentists and oral health technicians (OHTs) who work in Basic Health Units in the city of Curitiba, PR, Brazil, regarding cases of abuse against children and adolescents. Methods: In this observational study, three hundred eighty-three questionnaires (validated for Brazilian Portuguese) were sent to dentists and OHTs who work in public health units. The response rate was $38.12 \%(n=146)$ for dentists and $40 \%$ $(n=77)$ for OHTs. Results: The mean age of the dentists was $40 \pm 8.29$ years, and $53.43 \%$ treated more than 10 children per week. The OHTs' mean age was $45.39 \pm 9.71$ years, and $62.35 \%$ attended to more than 10 children per week. Although the dentists perceived 185 suspected cases of maltreatment, only $35.67 \%$ were reported to authorities. In the OHT group, $22.08 \%$ were reported to authorities. Sixty-eight dentists (47\%) and $11 \mathrm{OHTs}(14.28 \%)$ reported having treated at least one case of orofacial trauma in the previous 6 months, totalizing 166 orofacial traumas. About the mechanism for reporting suspected cases, $83 \%$ of the respondents knew how to report. Over $50 \%$ of the responses concerning why the professionals did not report cases of physical violence against children included fear of retaliation and difficulties in diagnosis. Conclusions: Suspected cases of maltreatment against children and adolescents are underreported. More information is required to recognize suspected maltreatment cases and notify authorities.
\end{abstract}

Keywords: child abuse; dentists; Public Health Dentistry.

\section{Introduction}

Received for publication: July 14, 2015 Accepted: September 26, 2015

Correspondence to: Estela Maris Losso

Rua Professor Pedro Viriato Parigot de Souza, 5300 Campo Comprido - CEP: 81280-330

Curitiba, PR, Brasil

Phone: +554133173454

E-mail: Iossoem@gmail.com
Children and adolescents are adversely affected by maltreatment because of their physical and psychological weakness and reliance on others ${ }^{1}$. According to the Brazilian Ministry of Health ${ }^{2}$ 107,572 cases of child abuse were reported in 2011. The Network of Protection for Children and Adolescents at Risk for Violence, an organization associated with the city of Curitiba, PR, Brazil, reported 5,371 suspected cases of child abuse in $2011^{3}$. Among them, $81.8 \%$ characterized as intrafamilial, of which $74.8 \%$ were cases of neglect and $12.1 \%$ were cases of physical aggression. The age of the children who suffered abuse ranged from 5 to 14 years $^{3}$.

Child abuse is defined as any action or omission that prejudices the physical and psychological wellbeing, freedom and children's right to full development. Child abuse can be classified as physical, sexual or psychological abuse or neglect ${ }^{1,4-5}$. Neglect was reported as the most common type of maltreatment ${ }^{3-4}$. In the United Kingdom $44 \%$ of all children were reported in child protection registers ${ }^{6}$. This indicates a failure of parents or guardians to meet the children's basic care 
and needs, including their oral heath needs, to enjoy adequate function and freedom from pain and infection ${ }^{5}$. The neglect of children's oral health may include the absence of managing oral hygiene and seeking dental treatment when needed, which can lead to dental caries, pain, poor dental growth and impaired quality of life. This situation should be recognized in dental offices if it is related to the guardian's lack of knowledge or neglect ${ }^{7}$.

Physical aggression can be considered a non-accidental injury inflicted on a child or adolescent by an individual with superior strength or age. The lesions may be multiple types, such as hematomas, burns, lacerations, cuts, bruises, contusions, and abrasions on the body, face, lips and mouth ${ }^{8}$. In the mouth, physical violence can be identified by dental trauma and soft tissue injuries that are not consistent with patient reports ${ }^{5,7}$.

Physical aggression may be identified in the dental office because $50-67 \%$ of physical injuries occur in the head, neck, face and mouth ${ }^{8}$. These regions are easily visible to the dentist. According to Cavalcanti ${ }^{9}$, the face accounted for $41 \%$ of the lesions, $55.6 \%$ of them were in the maxilla and $94.8 \%$ were in soft tissues.

In the Brazilian Basic Health Units, public health dentistry teams comprise dentists and oral health technicians (OHTs). These professionals, mainly the dentists, have legal, moral and ethical duty to notify the authorities suspected cases of child abuse, according to the Federal Constitution and Brazilian Statute of the Child and Adolescent ${ }^{10}$.

Previous studies reported the difficulties that dentists have to diagnose, document and report suspected cases of child abuse to authorities, resulting in underreporting the cases of aggression ${ }^{11-18}$. An Australian study evaluated the level of knowledge and attitudes among dental professionals on the important issue of child abuse. The authors observed under-reporting of suspected child abuse cases. Among the specialties, pediatric dentistry was responsible for $75 \%$ of the reports ${ }^{19}$. In Denmark, dentists and OHTs from public health dentistry reported more cases of maltreatment than private dental offices and all professionals reported the need for further information and training to recognize and report child abuse ${ }^{20}$. A Brazilian study evaluated the perceptions and attitudes of child abuse in pediatric dentistry and underreporting was also found. No significant difference was found between the places of work (public and private offices). Over $50 \%$ of pediatric dentists provided services at private offices, $25 \%$ provided services at public and private offices, $10 \%$ provided services at public healthcare offices only, and $10 \%$ were university professors ${ }^{17}$.

Child abuse is disturbingly common in today's society ${ }^{21}$. Considering the high proportion of orofacial injuries in victims of child abuse, the public health dentistry team has a strategic position to recognize and report suspected cases. However, the literature lacks data about the knowledge and attitudes of dental teams regarding child abuse. Thus, the aim of the present study was to evaluate the level of knowledge, attitudes and interest of public health dentistry teams (dentists and OHTs) who work in Basic Health Units in the city of Curitiba, PR, Brazil, regarding cases of abuse against children and adolescents.

\section{Material and methods}

This observational study was conducted after approval by the institutional Ethics Committee (Protocol no. 118/ 2011).

According to the Regional Dental Council of Paraná, the Basic Health Units of the city of Curitiba had 383 dentists and 194 OHTs in 2012. All these professionals were invited to participate in this study. Russell et al. ${ }^{22}$ developed the questionnaire $^{22}$, which was validated for Brazilian Portuguese by Marengo et al. ${ }^{23}$. This questionnaire has four parts. The first part refers to the social and demographic characteristics of the professionals. The second part refers to prior experience with maltreatment (including six yes/no closed-end questions). The third part refers to the healthcare professional's knowledge, diagnoses and attitudes, and includes six questions (one yes/no closed-end question, two questions with answers on a 0-10 scale and three open-ended questions). The fourth part refers to involvement with the subject of child abuse and includes three questions (two closed-end questions and one with answers on a 0-10 scale $)^{23}$.

The questionnaire was sent by internal communication to the dentists and OHTs in an envelope that contained the survey questionnaire, a letter of instruction for filling it and an informed consent form. Responses were anonymous. A deadline was set to complete and return the questionnaire. After this date, an electronic reminder was sent to the participants to increase the response rate.

The $\chi^{2}$ and Fischer tests were used to analyze the associations between variables (suspected cases of child abuse, notifications and time since graduation). A significance level of $5 \%$ was set for the statistical analyses.

\section{Results}

The initial response rate of the dentists was $33.15 \%$ $(n=127)$. After the electronic reminder, the response rate increased to $38.12 \%(n=146)$, among which $78.76 \%$ $(n=115)$ were female and $21.24 \%(n=31)$ were male. In the OHT group, the initial response rate was $34 \%(n=67)$; after the electronic reminder, the response rate increased to $40 \%$ $(n=77)$, among which $94.80 \%(n=73)$ were female and $5.20 \%(n=4)$ were male.

With regard to age, the dentists ranged from 24 to 60 years (mean: $40 \pm 8.29$ years), with $2-35$ years (mean: $18 \pm 8.15$ years) since graduation. The OHTs' ages ranged from 26 to 63 years (mean: $45.39 \pm 9.71$ years), with 5-31 years (mean: $17.55 \pm 6.09$ years) since graduation (Table 1). According to their places of work, $69 \%$ of the dentists worked at public offices, and $31 \%$ worked at both public and private offices. Most of the dentists $(53.43 \%)$ treated more than 10 children per week. The OHTs treated from 1 to 20 children per week, and $36.37 \%(n=28)$ treated $11-20$ children per week (Table 2). 
Table 1. Distribution of respondents according to years since graduation.

\begin{tabular}{lcl}
\hline $\begin{array}{c}\text { Time since } \\
\text { graduation (years) }\end{array}$ & Dentists $\%(\boldsymbol{n})$ & OHTs $\%(\boldsymbol{n})$ \\
$2-10$ & $26.71(39)$ & $18.18(14)$ \\
$11-20$ & $24.67(36)$ & $45.45(35)$ \\
$>20$ & $44.52(65)$ & $35.08(27)$ \\
No answer & $4.10(6)$ & $1.29(1)$ \\
\hline
\end{tabular}

Table 2. Number of children treated per week.

\begin{tabular}{lcc}
\hline $\begin{array}{l}\text { Number of children } \\
\text { treated per week }\end{array}$ & Dentists \% $(\boldsymbol{n})$ & OHTs \% ( $\boldsymbol{n})$ \\
$1-5$ & $10.96(16)$ & $9.09(7)$ \\
$6-10$ & $30.83(45)$ & $27.27(21)$ \\
$11-20$ & $41.79(61)$ & $36.37(28)$ \\
$>20$ & $11.64(17)$ & $25.98(20)$ \\
None & $4.10(6)$ & $1.29(1)$ \\
No answer & $0.68(1)$ & - \\
\hline
\end{tabular}

No significant association was found between the number of children seen per week and suspected cases of child abuse $\left(\chi^{2}=2.11, d f=2, p>0.10\right)$. The number of notifications by dentists was associated with the number of children seen per week $(p=0.029)$. For the OHTs, no association was found between the number of children seen and suspected cases of child abuse $\left(\chi^{2}=3.46, d f=2, p=0.17\right)$ or the number of notifications $\left(\chi^{2}=0.79, d f=2, p=0.67\right.$; Table 3$)$.

For dentists, a significant association was found between the time since graduation and suspected cases of child abuse $\left(\chi^{2}=7.35, d f=2, p<0.03\right)$. Most suspected cases of child abuse were found by the group of professionals with over 20 years since graduation $\left(\chi^{2}=6.28, d f=2, p<0.02\right.$; Table 3$)$.

For OHTs $(n=76)$, no association was found between the time since graduation and suspected cases of child abuse (time since graduation: 10 years, $p=0.69 ; 11-20$ years, $p=0.73 ;>20$ years, $p=0.64)$. The time since graduation was unrelated to notified cases (time since graduation: 10 years, $p=0.08 ; 11-20$ years, $p=0.08 ;>20$ years, $p=1.00$; Table 3).
For prior experience with suspected maltreatment cases against children and adolescents, $52,73 \%$ of the dentists $(n=77)$ and $46.75 \%$ of the OHTs $(n=36)$ examined suspected cases among their patients. Although the dentists suspected 185 cases of maltreatment, only $35.67 \%(n=66)$ were reported to authorities. In the OHT group, $22.08 \%(n=17)$ notified authorities about suspected cases of child abuse.

Sixty-eight dentists (47\%) and 11 OHTs (14.28\%) reported having treated at least one case of orofacial trauma in the previous 6 months, totalizing 166 orofacial traumas.

In the self-assessment on a $0-10$ scale about their perceived ability to identify the signs and symptoms of child abuse, the medians were six $(n=146)$ and seven $(n=74)$ for dentists and OHTs, respectively. As to the ability to diagnose physical aggression, the medians were five $(n=143)$ for dentists and six $(n=73)$ for OHTs. For the professionals who reported that the subject of maltreatment was important, the medians were nine $(n=144)$ and eight $(n=76)$ for the dentists and OHTs, respectively.

With regard to their understanding of notification mechanisms, 117 dentists (63.83\%) and 70 OHTs 90.90\%) reported that they were able to perform the notifications.

In response to questions about the reasons why child abuse cases were not reported, the most common reasons were fear and threats of retaliation and lack of knowledge in diagnosing, $26.95 \%$ of the OHTs and $44.18 \%$ of the dentists stated that they did not report such cases because of fear and threats of retaliation (Figure 1). Other reasons included connivance of the involved family, lack of interest by the professionals, lack of commitment by the professionals, cultural issues, fear of consequences for the victim and/or their family, lack of a relationship with the patients, omission, no quick resolution, lack of time for questioning and socioeconomic factors (Figure 1).

For possible ways to motivate the professionals' notification of child abuse cases, the most cited were courses, lectures, campaigns, and establishing clinical guidelines for managing suspected child abuse cases (Figure 2).

With regard to their interest in obtaining more information about child abuse, $97 \%$ of the dentists $(n=142)$

Table 3. Distribution of the number of children treated per week by dentists and OHTs and time since graduation of the professionals according to suspected maltreatment cases and notifications.

\begin{tabular}{|c|c|c|c|c|}
\hline \multirow{2}{*}{$\begin{array}{l}\text { Number of children } \\
\text { treated per week }\end{array}$} & \multicolumn{2}{|c|}{ Suspected child abuse $\%(n)$} & \multicolumn{2}{|c|}{ Notifications \% (n) } \\
\hline & Dentists & OHTs & Dentists & OHTs \\
\hline $1-10$ & $27.03(50)^{\mathrm{a}}$ & $30.55(11)^{a}$ & $10.61(7)^{b}$ & $17.64(3)^{a}$ \\
\hline $11-20$ & $36.23(67)^{\mathrm{a}}$ & $33.33(12)^{\mathrm{a}}$ & $43.94(29)^{a}$ & $35.30(6)^{\mathrm{a}}$ \\
\hline$>20$ & $36.74(68)^{a}$ & $36.12(13)^{\mathrm{a}}$ & $45.45(30)^{a}$ & $47.06(8)^{a}$ \\
\hline \multirow[t]{2}{*}{ Years since graduation } & \multicolumn{2}{|c|}{ Suspected child abuse \% (n) } & \multicolumn{2}{|c|}{ Notifications \% (n) } \\
\hline & Dentists & OHTs & Dentists & OHTs \\
\hline$\leq 10$ & $17.30(32)^{\mathrm{a}}$ & $14.29(5)^{\mathrm{a}}$ & $7.58(5)^{a}$ & - \\
\hline $11-20$ & $18.38(34)^{a}$ & $48.57(17)^{a}$ & $18.18(12)^{a}$ & $41.18(7)^{a}$ \\
\hline$>20$ & $64.32(119)^{b}$ & $37.14(13)^{\mathrm{a}}$ & $74.24(49)^{b}$ & $58.82(10)^{a}$ \\
\hline
\end{tabular}

Statistically significant differences are represented by different letters in the columns (Fisher exact test and $c^{2}$ test, $p<0.05$ ) 


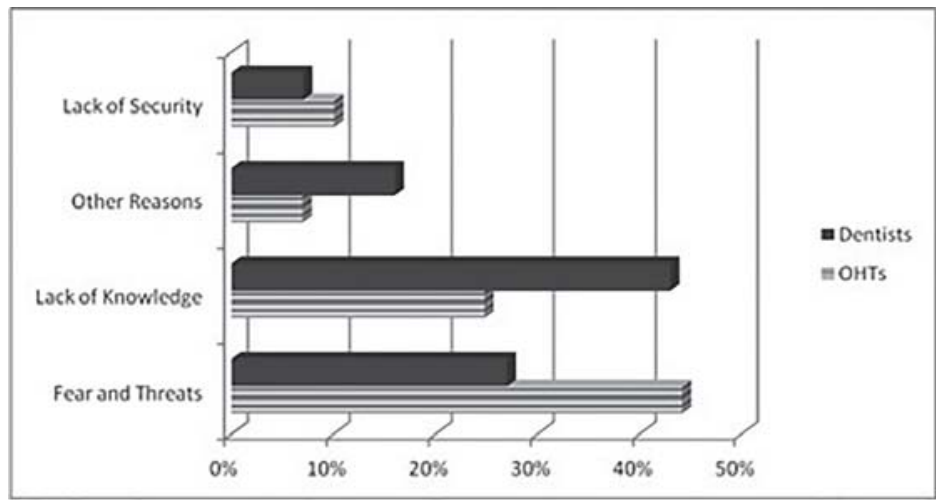

Fig. 1. Primary reasons reported by dentists and OHTs for not reporting abuse.

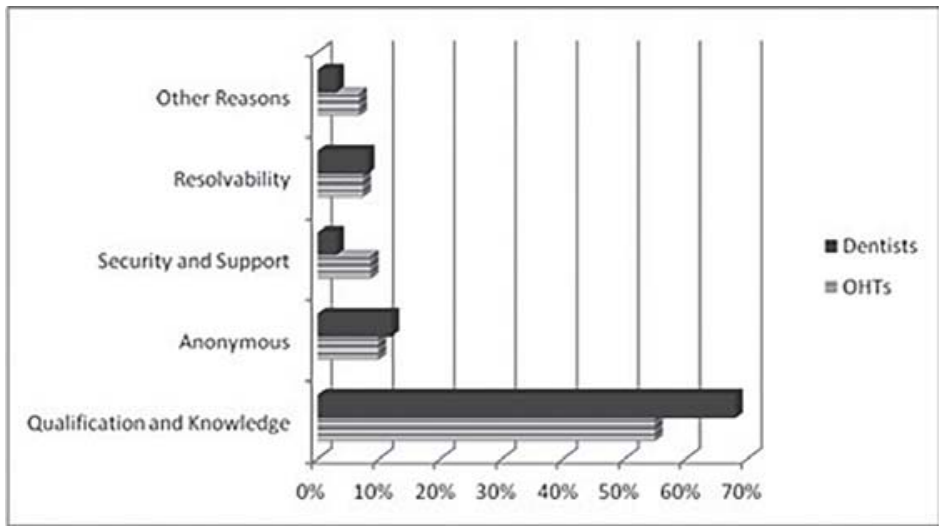

Fig. 2. Possible methods reported by dentists and $\mathrm{OHTs}$ for motivating professionals notifications of child abuse.

and $93.51 \%$ of the OHTs $(n=72)$ reported they wished to have more information about the management of maltreatment cases and how to identify and report suspected cases, in addition to including the subject of maltreatment in their graduate studies.

\section{Discussion}

The initial response rate was $38 \%$ for the dentists and $40 \%$ for the OHTs, which is reasonable for this type of study, considering that the professionals work with time constraints and a high patient demand. Similar rate was found by Lazenbatt and Freeman ${ }^{6}$, who evaluated health professionals in the United Kingdom.

The survey revealed a high prevalence of female dentists working at Basic Health Units in the city of Curitiba ${ }^{17}$. In other countries ${ }^{11,16,20,24}$, studies reported a prevalence of males worked in public health services.

The respondents were included in the present study regardless of their time since graduation, but most of the professionals who returned the questionnaire had more than 20 years since graduation, demonstrating that their interest in the subject of child abuse was independent of the time since graduation ${ }^{14,24}$.

With regard to working places, $69 \%$ of the respondents worked at public offices only, which was expected because the sample was selected from public health services. Moreover, $31 \%$ of the dentists worked in private offices. These data are consistent with a previous Brazilian study, in which most professional respondents worked at public health services only ${ }^{14}$. The OHT group worked exclusively at public health services in public health dentistry teams. These professionals should be qualified to assist dentists to document suspected cases of child abuse and thus actively participate in the efforts against child maltreatment.

Most notifications of suspected cases were found by the dentist group that treated more than 11 children per week. However, this association was not found for the OHT group. This may be explained by the ability to recognize signs and symptoms of suspected cases and notify authorities. Although the professionals suspected cases of child abuse, there was under-reporting ${ }^{25}$. Unfortunately, this is in agreement with substantial data from other countries $6,15,17,24,26$.

Among the reasons why abuse was under-reported, the professionals frequently mentioned fear, threats of retaliation, uncertainty in the diagnosis, and lack of knowledge about how to report suspected cases. These reasons were also reported in several previous studies, demonstrating the difficulties that professionals have around the world ${ }^{8,20,22}$. Thus, the decision to report a suspected case depends on extant legislation, personal and professional factors and peculiarities of the case $^{27}$. 
In the present study, an important issue that the professionals mentioned is the need for anonymity after notification, which is warranted by Brazilian Guardianship Councils. Health professionals in Brazil have legal duty to report cases of suspected abuse against children and adolescents, based on the Brazilian Federal Constitution and its Statute of Children and Adolescents. Moreover, protection of children is obligatory for every citizen ${ }^{10}$.

Another important point is the definition of "notification" as described by the Brazilian Ministry of Health" "an instrument for ensuring legal and social protection of children and adolescents, allowing professionals from health, education, social assistance, as well as community councils and justice to take immediate action to stop the violence."

Some political actions should be instituted to increase notifications by professionals, such as providing more information about child abuse, integration among multidisciplinary health professionals who work at public services, and senior health professionals providing support to health teams. Ideally, mutual support among professionals is required, including sharing the knowledge and opinions, and adopting guidelines for protective actions. These actions between colleagues and senior health professionals would make them feel safer to diagnose and report suspected cases of violence. The lack of information about child abuse was reported by Luna et al. ${ }^{28}$ who found that $69 \%$ of the health professionals who work at Basic Health Units never received training on violence against children and adolescents. Training of dental staff should be routine and thus increase the ability to recognize the signs and symptoms of abuse and provide security for reporting suspected cases.

Previous studies that were conducted in several countries reported dentists' difficulties to diagnose, document, and report suspected abuse cases to authorities ${ }^{6,12-13,17,20,24,29}$. Although notifications were higher in the present study compared with Russell et al. ${ }^{22}$, Brazilian professionals should be trained to improve their ability to recognize the signs and symptoms of child abuse and increase their confidence in reporting suspected cases of child abuse to authorities.

With regard to the respondents' interest in detecting physical child abuse, the dentists reported a higher interest compared with Russell et al. ${ }^{22}$, who found that some dentists did not perceive the relevance of child abuse cases and saw it as a cumbersome obligation. More than $50 \%$ of cases of physical child abuse involve the head, face, neck and mouth, which are easily visible to dentists and OHTs. Therefore, these professionals are sometimes the first to attend to such victims

Information about child abuse is needed to modify the actions of health professionals when faced with child abuse cases and increase notifications of suspected cases. Integral and multidisciplinary actions are needed to face this serious global problem ${ }^{29}$.

It may be concluded that fear and lack of knowledge about diagnosing violence against children and adolescents and reporting such cases are barriers to recognizing and reporting suspected cases, thus resulting in under-reporting. Public health dentistry teams showed interest in learning more about and reporting child abuse, thus indicating the importance of establishing political actions to educate and support these teams.

\section{Acknowledgements}

The authors thank the oral health professionals in the city of Curitiba.

\section{References}

1. Brazil. Ministry of Health, Department of Health Policy. Family violence guidelines for the practice in service. Brasília: Ministry of Health; 2002 [cited 2015 Oct 19]. (Cadernos de Atenção Básica, 8). Available from: http://bvsms.saude.gov.br/bvs/publicacoes/cd05_19.pdf.

2. Brazil. Ministry of Health. DATASUS. TabNet Linux 2.4: Domestic violence, sexual and/or other violence - Sinan [cited 2015 Oct 19]. Available from: http://dtr2004.saude.gov.br/sinanweb/tabnet/tabnet?sinannet/ violencia/bases/violebrnet.def.

3. Muraro HMS. Network for the protection of children and adolescents at risk for violence. Curitiba: Secretary of Helth; 2012 [cited 2015 Oct 15]. Available from: http://www.crianca.mppr.mp.br/arquivos/File/ curso_de_atualizacao/2012/a3_rede_de_protecao_mp_2012.pdf.

4. Valente LA, Dalledone M, Pizzatto E, Zaiter W, de Souza JF, Losso EM. Domestic violence against children and adolescents: prevalence of physical injuries in a southern Brazilian metropolis. Braz Dent J. 2015; 26: 55-60.

5. American Academy of Pediatrics Committee on Child Abuse and Neglect; American Academy of Pediatric Dentistry; American Academy of Pediatric Dentistry Council on Clinical Affairs. Guideline on oral and dental aspects of child abuse and neglect. Pediatr Dent. 2008-2009; 30(7 Suppl): 86-9.

6. LazenbattA, Freeman R. Recognizing and reporting child physical abuse: a survey of primary healthcare professionals. JAdv Nurs. 2006; 56: 227-36.

7. Tsang A, Sweet D. Detecting child abuse and neglect-are dentists doing enough? J Can Dent Assoc. 1999; 65: 387-91.

8. Cairns AM, Mok JY, Welbury RR. Injuries to the head, face, mouth and neck in physically abused children in a community setting. Int J Paed Dent. 2005; 15: 310-8.

9. Cavalcanti AL. Prevalence and characteristics of injuries to the head and orofacial region in physically abused children and adolescents-a retrospective study in a city of the Northeast of Brazil. Dent Traumatol. 2010; 26: 149-53.

10. Brazil. Status of children and adolescents. Law No. 8069 of July 13, 1990 [cited 2010 Aug 23]. Available from: http://www.planalto.gov.br/ccivil_03/ LEIS/L8069.htm.

11. Bsoul SA, Flint DJ, Dove SB, Senn DR, Alder ME. Reporting of child abuse: a follow-up survey of Texas dentists. Pediatr Dent. 2003; 25: 541-5.

12. Thomas JE, Straffon L, Inglehart MR. Knowledge and professional experiences concerning child abuse: an analysis of provider and student responses. Pediatr Dent. 2006; 28: 438-44.

13. Manea S, Favero GA, Stellini E, Romoli L, Mazzucato M, Facchin P. Dentists' perceptions, attitudes, knowledge, and experience about child abuse and neglect in northeast Italy. J Clin Ped Dent. 2007; 32: 19-25.

14. Granville-Gracia AF, Silva MJF, Menezes VA. Abuse of Children and Adolescent: A Study in the City of São Bento do Una, PE, Brazil. Pesqui Bras Odontopediatria Clin Integr. 2008; 8: 301-7.

15. Sonbol HN, Abu-Ghazaleh S, Rajab LD, Baqain ZH, Saman R, Al-Bitar ZB. Knowledge, educational experiences and attitudes towards child abuse amongst Jordanian dentists. Eur J Dent Educ. 2012; 16: e158-65. 
16. Laud A, Gizani S, Maragkou S, Welbury R, Papagiannoulis L. Child protection training, experience, and personal views of dentists in the prefecture of Attica, Greece. Int J Paediatr Dent. 2013; 23: 64-71.

17. El Sarraf MC, Marego G, Correr GM, Pizzatto E, Losso EM. Physical child abuse: perception, diagnosis, and management by Southern Brazilian pediatric dentists. Pediat Dent. 2012; 34: e72-6.

18. Thomas JE, Straffon L, Inglehart MR. Child abuse and neglect: dental and dental hygiene students' educational experiences and knowledge. J Dental Educ. 2006; 70: 558-65.

19. John V, Messer LB, Arora R, Fung S, Hatzis E, Nguyen T, et al. Child abuse and dentistry: a study of knowledge and attitudes among dentists in Victoria, Australia. Aust Dent J. 1999; 44: 259-67.

20. Uldum B, Christensen HN, Welbury R, Poulsen S. Danish dentists' and dental hygienists' knowledge of and experience with suspicion of child abuse or neglect. Int J Paediatr Dent. 2010; 20: 361-5.

21. Colucci E, Hassan G. Prevention of domestic violence against women and children in low-income and middle-income countries. Curr Opin Psychiatry. 2014; 27: 350-7.

22. Russell M, Lazenbatt A, Freeman R, Marcenes W. Child physical abuse: health professionals' perceptions, diagnosis and responses. Brit J Community Nurs. 2004; 9: 332-8.

23. Marengo G, Paola AP, Ferreira FM, Pizzatto E, Correr GM, Losso EM. Child abuse: validation of a questionnaire translated into Brazilian Portuguese. Braz Oral Res. 2013; 27:163-8.

24. Owais Al, Qudeimat MA, Qodceih S. Dentists' involvement in identification and reporting of child physical abuse: Jordan as a case study. Int J Paediatr Dent. 2009; 19: 291-6.

25. Azevedo MS, Goettems ML, Brito A, Possebon AP, Domingues J, Demarco FF, et al. Child maltreatment: a survey of dentists in Southern Brazil. Braz Oral Res. 2012; 26: 5-11.

26. Cairns AM, Mok JY, Welbury RR. The dental practitioner and child protection in Scotland. Brit Dent J. 2005; 199: 517-20; discussion 512; quiz 30-1.

27. Gonçalves HS, Ferreira AL. Health professionals' reporting of family violence against children and adolescents. Cad Saude Publica 2002; 18 : 315-9.

28. Luna GL, Ferreira RC, Vieira LJES. Mandatory reporting of child abuse by professionals of Family Health Teams. Cienc Saude Colet. 2010; 15 : 481-91.

29. Deshpande A, Macwan C, Poonacha KS, Bargale S, Dhillon S, Porwal $P$. Knowledge and attitude in regards to physical child abuse amongst medical and dental residents of central Gujarat: A cross-sectional survey. J Indian Soc Pedod Prev Dent. 2015; 33: 177-82. 